\title{
An Experience of Limbal Autologous Free Conjunctival Grafting in Cases of Pterygium in Rural Western Hilly Region of Nepal
}

\author{
Bastola $P^{1^{*}}$ \\ ${ }^{1}$ Nepalgunj Medical College, Kohalpur, Banke, Nepal
}

\section{* Corresponding Author: \\ Dr. Pradeep Bastola Consultant Ophthalmologist, Assistant Professor Nepalgunj Medical College, Kohalpur, Banke, Nepal Email address: pbs_dinku@yahoo.com}

\section{Citation}

Bastola P. An experience of Limbal autologous free conjunctival grafting in cases of pterygium in rural Western hilly region of Nepal. Nepal Journal of Medical Sciences. 2012; 1(1): 11-14.

\begin{abstract}
Background: The study was set in a remote western hilly part of Nepal in the communities of Gulmi, Arghakhnchi and Palpa district of Nepal after seeing the high prevalence of pterygium in those communities. The main purpose of the study was to determine the outcome of free limbal autologous conjunctival grafting from supero temporal quadrant of the eyeball, in cases of pterygium undergoing surgery.

Methods: Patients undergoing surgery were evaluated preoperatively, in all cases limbal based supero temporal free autologous conjunctival graft was used, except in cases where it was contraindicated. All the patients' data were enrolled in to a specifically made proforma for the study. Cases undergoing surgery were followed up, up to one year period. Statistical analysis was performed using Statistical Package for Social Services version 12.0 (SPSS).
\end{abstract}

Results: Hundred and fifteen eyes of 115 patients were included in the study. Ten $(8.6 \%)$ cases had primary nasal and temporal pterygia both, while five $(4.3 \%)$ cases in the study were recurrent pterygium. Commonest complication post operatively encountered were foreign body sensation, ocular discomfort, redness, while two cases had flap retraction which was sutured back. None of the patients had recurrence of the pterygia till the last follow up period.

Conclusion: This study has shown that free limbal based autologous conjunctival graft is one of the safe surgical techniques for Pterygium treatment with excellent outcome especially in those parts of area where modern pterygium surgery are difficult to do with various restrictions.

Keywords: Pterygium; limbal autologous grafting; graft retraction

\section{Background:}

$P_{\text {terygium is a wing shaped conjunctival encroachment }}$ onto the cornea generally situated on the nasal side. It sometimes occurs both nasally and temporally, and rarely only on the temporal side. ${ }^{1}$ During the past decade numerous authors have been interested in corneal stem cells. These are situated in the deeper layers at the limbus. When deeper parts of the limbal epithelium is damaged or removed. Various changes occur in the limbal region. These signs are also seen in pterygia; thus some authors speculate that pterygium manifests limbal stem cell deficiency. ${ }^{2}$
Though the exact prevalence of pterygium in Western hilly region of Nepal is not known but cases of pterygium are seen quite frequently in opthalmic OPDs. Due the recurrent nature of the disease it is suspected that it is not an uncommon cause of occular morbidity

Surgical removal is the treatment of choice. Pterygium can be treated by various modalities of surgery, however, in Nepal modern advanced surgical treatment for pterygium (Like amniotic membrane grafts, cut and paste technique, pterygium extended removal followed by extended conjunctival grafting commonly known as PERFECT) are 
either in primitive stage or has not begun in many centres. Hence, an acceptable and effective treatment modality has been a long felt need in these cases.

Free limbal autologous conjunctival grafting can be performed relatively easily in Western rural hilly region of Nepal. Many authors consider autologous conjunctival grafting to be the best method; giving both low recurrence rate and high safety. ${ }^{3-5}$

However there has been no study in western hilly region of Nepal which has reported the outcome of free limbal autologous conjunctival grafting in pterygium. It is important to know the outcome of this type of surgical procedure in the setting of rural Western hilly region of Nepal because other modern pterygium surgeries are difficult to be performed because of various constraints. Hence this study was carried out with the main purpose of determining the outcome of free limbal autologous conjunctival grafting from supero temporal quadrant of the eyeball, in rural Western hilly region of Nepal.

\section{Methods:}

This was a hospital/community based prospective, nonrandomized, interventional study, the study was carried out by Palpa Lions Lacoul Eye Hospital, Tansen, Palpa in the remote hilly regions of Palpa, Gulmi and Arghankhanchi Districts of Nepal from June, 2009 to June, 2011. This study was registered with the Institutional review board and an approval was taken to carry out the study from the ethical committee of Lumbini Eye Institute, Nepal and besides it strongly adhered to the Tenets of the Declaration of Helsinki.

All the cases willing for pterygium surgery were included in the study and were selected from Palpa Lions Lacoul Eye Hospital or from community after getting informed consent. Patients who did not come for follow up were excluded from the study. Previous history of cataract surgery, filtering surgery, patient not willing to be part of the study were also excluded from the study. All patients were evaluated in detail from ocular perspective. All patients before surgery were subjected for lignocaine test; Diabetes Mellitus and hypertension were ruled out.

All patients underwent pterygium surgery under peribulbar local anesthesia. Single surgeon performed all the surgeries. Supero temporal portion of the eyeball was chosen for limbal based conjunctival autologous graft. After removal of the pterygia in patients, Tenon's capsule was removed extensively and wet field minimal/no cautery was used to maintain haemostasis, which was used as per requirement. An appropriate graft was taken and was sutured with the adjacent conjunctiva with 10-0 nylon in the pterygium excision site.

Patients were evaluated in the first post-operative day, at two weeks, six weeks and at one year time. Last follow up was carried out in June 2011, for the cases undergoing surgery one year back. Post operatively, patients were prescribed topical steroid - antibiotic combination eye drops and ointment. The nylon sutures were removed at two weeks or at six weeks follow up, while the medication was tapered over four weeks period from the first follow up at two weeks. All the findings were noted in the proforma specifically designed for the study and the data was analysed by statistical package for social service (SPSS) version 12.0.

\section{Results:}

A total of 115 patients with 115 eyes undergoing surgery were studied during the period. Out of 115 eyes undergoing pterygium surgery, 70 (approximately 69\%) patients were females while 45 eyes (39\%) were of male patients. Ten cases had both nasal as well as temporal pterygia in a same eye. While five cases were of recurrent pterygia. Age of the patients ranged from 19 years to 75 years, mean age of the patients was 35 years with standard deviation of \pm 18 .

Average time taken to perform the surgery excluding patient preparation, local anaesthesia in this study was 20 minutes. Commonest complications post operatively encountered were foreign body sensation, ocular discomfort, redness, graft oedema, subconjunctival hemorrhage, while two cases had flap retraction which was sutured back (Table 1).

Table 1: showing complications encountered during the study.

\begin{tabular}{lcl}
\hline \multicolumn{1}{c}{ Complications } & $\begin{array}{c}\text { Number of eyes } \\
(115 \text { total })\end{array}$ & Percentage \\
\hline Foreign body sensation & 60 & $52.1 \%$ \\
Ocular discomfort & 56 & $48.6 \%$ \\
Significant redness & 55 & $47.8 \%$ \\
Graft oedema & 10 & $8.6 \%$ \\
Subconjunctival haemorrhage & 9 & $7.8 \%$ \\
Flap retraction & 2 & $1.7 \%$ \\
\hline
\end{tabular}

\section{Discussion:}

This was a study done in rural community of western hilly region of Nepal, in a hospital/community based approach. This kind of study has been done already in developed countries and in western world. Conjunctival autologous free grafting has been accepted as one of the best surgical methods for pterygium surgery. ${ }^{6}$ This study aimed at finding the outcome of conjunctival free grafting in pterygium 
treatment in needy population of rural Nepal, where the advanced Ophthalmic ocular surgeries are not practiced because of various reasons.

There have been many attempts to optimize pterygium surgery and at present, a wide variety of techniques are in use, from the bare sclera technique without using a microscope to very complex approaches like amniotic membrane transplantation ${ }^{5}$ and lamellar keratoplasty. ${ }^{7}$ The basic aim of pterygium treatment is to excise the pterygium and prevent its recurrence and other complications as well.

Regarding autologous conjunctival graft transplantation, it's been proven now it avoids the risk of scleral necrosis associated with the alternative adjunctive therapies at the cost of increased surgical time and early postoperative discomfort. ${ }^{8}$ Males and patients below 40 years face greater risk of recurrence. Bare sclera technique has an unacceptably high recurrence rate and it's popularity for pterygium treatment is decreasing with each passing day, hence other modalities for pterygium treatment are becoming more popular now. ${ }^{9}$

Current study showed no recurrence of any pterygia excised, however the duration of follow up was only one year. Excision of pterygium with a conjunctival autologous free grafting has no procedure-specific added surgical risks but the use of sutures, plasma derived products such as fibrin glue and use of adjunctive do have their own kinds of complications like discomfort, scarring, or infection. Plasma derived products such as fibrin glue may cause hypersensitivity reactions. In a recent study where neither suture nor fibrin glue was used, the study showed excellent results with zero recurrence and very minimal complications. This surgical technique will probably be accepted more as the time taken for the surgery is shorter in autologous conjunctival free grafting with use of sutures. ${ }^{10}$

This study has shown that free limbal based autologous conjunctival graft is one of the best surgical technique for pterygium surgery with very minimal or no recurrence rate. The relatively long surgical time and microsurgical methods required to perform the procedure properly have hindered its acceptance as the mainstream approach to pterygium management. Long-term follow-up is needed for better discernment of the surgical results. ${ }^{1}$

Use of topical anesthesia have been practiced widely in developed countries for pterygium excision with autologous free conjunctival grafting, in a recent study ropivacaine as an anaesthetic agent was found to be safe and effective in pterygium surgery. The Long-lasting anesthesia with this agent permitted performing the surgical procedures with autologous conjunctival graft and fibrin glue to attach the flap with low pain perceived by the patients, low surgical invasivity, and short duration of surgery. In this study topical anesthesia was not used to perform the surgery. However in modern times, it is strongly advised to use topical anesthesia for pterygium surgery. ${ }^{11}$ Similarly, in a comparative study regarding use of fibrin glue versus sutures for autologous conjunctival grafting for pterygium surgery, it was concluded that using fibrin glue in pterygium surgery with conjunctival autografting significantly reduces surgery time, improves postoperative patient comfort, and results in a lower recurrence rate compared with suturing. ${ }^{12}$

In this study sutures were used due to lack of availability of plasma derived fibrin products, with very acceptable outcomes. Though it is recommended that use of fibrin glue is a better option when available for conjunctival autologous free grafting for pterygium surgery. In an interesting study, where the use of fibrin glue versus use of sutures (vicryl) in amniotic membrane transplant for primary pterygium surgery concluded that amniotic membrane grafts can be successfully attached without any major complication in patients undergoing pterygium surgery. In addition, it is effective in shortening the duration of surgery and preventing post-operative discomfort. Although there seems to be no difference in the recurrence rates and cosmetic outcomes between both groups. ${ }^{13}$

The use of amniotic membrane transplant for pterygium surgery in Nepal is in primitive stage and not really used widely, which also signifies the fact of use of conjunctival free autologous graft as described in this study of ours, which is very safe and effective. Overall this study can conclude that in a country like Nepal, use of free conjunctival autologous grafting is a very safe, effective, cheap option of treatment for pterygium with minimal recurrence or no recurrence and very few reversible complications.

\section{Conclusion:}

Though, with so much of advancement in surgical treatment of pterygium surgery, an autologous limbal based conjunctival free grafting from supero temporal region of the eyeball still holds its value in effective pterygium surgery. Similar studies from other parts of Nepal would help to find out the outcomes of pterygium surgery.

\section{References:}

1. Koranyi G, Seregard S, Kopp ED. Cut and paste: a no suture, small incision approach to pterygium surgery. Br J Ophthalmol 2004;88:911-4. 
Original Article | Bastola P, limbal autologous free conjunctival grafting in Pterygium.

2. Nakaishi H, Yamamoto M, Ishida M. Pingueculae and pterygia in motorcycle policemen. Ind Health 1997;35:325-9.

3. Kenyon KR, Wagoner MD, Hettinger ME. Conjunctival autograft transplantation for advanced and recurrent pterygium. Ophthalmology 1985;92:1461-70.

4. Chen PP, Priyasu G, Kaza V. A randomized trial comparing mitomycin $\mathrm{C}$ and conjunctival autograft after excision of primary pterygium. Am J Ophthalmol 1995;120:151-60.

5. Prabhasawat P, Barton K, Burkett G. Comparison of conjunctival autografts, amniotic membrane grafts, and primary closure for pterygium excision. Ophthalmology 1997;104:974-85.

6. Allan BD, Short P, Crawford GJ. Pterygium excision with conjunctival auto grafting: an effective and safe technique. Br J Ophthalmol 1993;77:698-701.

7. Simona F, Tabatabay A, Leuenberger M. Lamellar corneal graft in the treatment of pterygium. A 10 year retrospective study of the recurrence and changes of astigmatism. J Fr Ophtalmol 1988;11:759-63.

8. Snibson R. An evidence-based appraisal of treatment options. In: Taylor HR, ed. Pterygium. The Hague: Kugler Publications, 2000:125-39.
9. Fernandes M, Sangwan S, Bansal A, et al. Outcome of pterygium surgery: analysis over 14 years. Eye 2005:19;1182-90.

10. De Wit D, Athanasiadis I, Sharma A et al. Sutureless and glue-free conjunctival autograft in pterygium surgery: a case series. Eye 2010;24:1474-7.

11. Caccavale A, Romanazzi F, Imparato $\mathrm{M}$, et al. Ropivacaine for topical anesthesia in pterygium surgery with fibrin glue for conjunctival autograft. Cornea 2010;29:375-6.

12. Karalezli A, Kucukerdonmez C, Akova YA, et al. Fibrin glue versus sutures for conjunctival autografting in Pterygium surgery: A Prospective Comparative Study. Br J Ophthalmol 2008;92:1206-10.

13. Karalezli A, Akova YA, Borazan M. Amniotic membrane transplantation using fibrin glue in pterygium surgery: a comparative randomised clinical trial. Eye 2010;24:558-66. 